\title{
Disability as Diversity in Higher Education
}

Emily M. Burns

Virginia Polytechnic Institute and State University

Follow this and additional works at: https://ecommons.luc.edu/jcshesa

Part of the Higher Education Commons

\section{Recommended Citation}

Burns, Emily M. (2020). Review of [Disability as Diversity in Higher Education: Policies and Practices to Enhance Student Success edited by Kim, E., \& Aquino, K. C.] New York, NY: Routledge Taylor and Francis Group.

This Book Review is brought to you for free and open access by the Journals and Magazines at Loyola eCommons. It has been accepted for inclusion in Journal of Critical Scholarship on Higher Education and Student Affairs by an authorized administrator of Loyola eCommons. For more information, please contact ecommons@luc.edu.

\section{(c) $(1) \ominus$}

This work is licensed under a Creative Commons Attribution-Noncommercial-No Derivative Works 3.0 License. 
Volume 5, Issue 2

Journal of Critical Scholarship on Higher Education and Student Affairs

\section{Book Review}

\section{Disability as Diversity in Higher Education}

\section{Policies and Practices to Enhance Student Success}

Emily M. Burns, Virginia Polytechnic Institute and State University

\section{- Abstract -}

College students with disabilities experience many barriers to postsecondary education including disability documentation requirements, social exclusion, inaccessible course design, and ostracizing campus environments. Most postsecondary leaders regulate disabled students to disability services offices, worrying about adherence to disability laws. Contributors to Disability as Diversity in Higher Education: Policies and Practices to Enhance Student Success, edited by Kim \& Aquino (2017), challenge higher education personnel to implement intentional strategies that would include disabled students in all aspects of campus life.

Keywords: disability, higher education, postsecondary education, diversity, access, inclusion

ISSN 2377-1306

(C) 2020

All rights reserved for the authors of this study. Journal of Critical Scholarship on Higher Education and Student Affairs is an open access journal and all pages are available for copying and distribution under a Creative Commons Attribution/Non-Commercial/ No Derivative works license. Any authorized work must be properly attributed to the author(s). Work cannot be used for commercial means or changed in any way. 
Kim, E., \& Aquino, K. C. (Eds.). (2017). Disability as diversity in higher education: policies and practices to enhance student success. New York, NY: Routledge Taylor and Francis Group.

"Good access is seamless, and available without individual requests" (Kroeger \& Kraus, 2017, p. 228).

\section{Review}

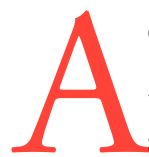
ccess to college courses, events, and housing requires disabled students to make individual accommodation requests to disability services offices. Disability laws mandate this individualized access for students with disabilities. How might college administrators broaden access for disabled students beyond the bare minimum required by law? Kim \& Aquino (2017), editors of Disability as diversity in higher education: Policies and practices to enhance student success, compile valuable chapters on strategies and techniques to transform college campuses into seamlessly accessible environments. Contributors, from postsecondary research groups and institutions, contend that access for disabled students should be an essential component of campus inclusion efforts.

The varying language used to refer to people with disabilities in this book strengthens the need to incorporate disability education into inclusion efforts. Chapters in this work use both identity-first language (i.e., disabled students) and person-first language (i.e., students with disabilities) to refer to disabled individuals. Readers without context on the development of varying language within postsecondary disability communities (e.g., Hutcheon \& Wolbring, 2012) might find this inconsistency confusing. This book review reflects the language in the book by including both identity-first and person-first language.

\section{Book Summary}

This text describes literature reviews, research, and programs that position disability as an integral part of diversity. In the preface, Kim and Aquino explain that campus diversity frameworks consistently include race, ethnicity, gender, and sexual orientation, but often exclude disability. Kim and Aquino argue that disabled people are members of a minority group that experience discrimination and injustice. All contributing authors approach disability from a social model perspective, asserting that disability is the result of physical and societal barriers (e.g., Martin, 2012).

Part 1 includes Chapters 1-3 and focuses on the implementation of theories related to disability inclusion and research. Chapter 1, by Yuknis and Bernstein, advocates for inclusive teaching practices that foster comfortable environments for students with hidden disabilities to disclose their needs to professors. Their new framework-culturally relevant disability pedagogy—offers teaching techniques that value culture and disability. All students learn about barriers and work together to remove them. The authors use disability-related literature to validate this new framework.

In Chapter 2, Shallish explains the urgency to include disability in campus diversity efforts. Shallish's qualitative study of 23 diversity officers at six northeast college campuses applies Taylor's (2011) description of disability studies theory. Disability studies frames ableism as the result of biased policies and practices. The study's results illuminate institutional barriers to inclusion faced by disabled students from low socio-economic backgrounds. Findings also highlight diversity officers' ableist views toward disabled students who have intersecting marginalized identities (e.g., disabled queer students; disabled students of color; etc.).

Chapter 3 presents Miller, Wynn, and Webb's reflections after interviewing disabled, queer students. They implement McRuer's (2006) crip theory framework to promote disability identity as desirable and worthwhile. The authors recognize their biases and disclose their concerns related to capturing students' lived experiences. Miller, Wynn, and Webb also describe their hopes of promoting full inclusion of disabled queer students in college environments. Find- 
ings emphasize the need to ensure a multiple-identity approach to campus inclusion efforts.

Chapters 4-7 make up Part 2 and emphasize the participation of students with disabilities in postsecondary education. Aquino, Taghreed, and Kim, in chapter 4, summarize a study of contentment levels of "different diverse groups including students with self-identified disabilities" (p. 48). Disabled students reported lower sense of belonging scores than other underrepresented students in the study. The authors found that students with "more than one minority category" (Aquino et al., 2017, p. 58) were more likely to experience prejudice than students who self-identified in only one underrepresented category.

In Chapter 5, Kimball, Friedensen, and Silva explore engagement levels of eight college students with learning disabilities. Students reported classroom engagement barriers related to time management, exams, and note-taking. Living on campus and participation in mentoring programs enhanced engagement for these students. The authors argue for both social and academic support for students with disabilities.

In Chapter 6, Hadley and Archer discuss barriers to education experienced by students with learning disabilities found in the literature. One major barrier is the requirement to submit disability documentation to access accommodations. College students with learning disabilities must also adjust to accommodation changes and learn self-advocacy skills. The authors envision institutions that remove educational barriers for disabled students.

Pearson \& Sumura, in chapter 7 , report the results of a qualitative study on the type of access and use of space available for disabled students on college campuses. Results revealed regulated access to spaces for students with mobility disabilities, such as service entrances serving as accessible entrances to campus buildings and accessible classroom seating set apart from other classroom seats. The authors conclude that inaccessible furniture arrangements and building entrances reveal exclusionary practices toward disabled students.
Part 3 includes Chapters 8-11 and discusses the viewpoints of postsecondary administrators and faculty members. Chapter 8 describes a comprehensive literature review on postsecondary faculty members' and administrators' perceptions of disability. Faculty members reported feeling underqualified to teach students with disabilities. Student affairs professionals said they lacked information and skills for including disabled students in their extra-curricular programs (e.g., spring break trips, residence hall events, and diversity activities). Their findings from the literature support the authors' concluding argument that all faculty and staff need additional training to support disabled students.

Anicha, Ray, and Bilen-Green, in Chapter 9, focus on disability identity when hiring faculty members. They outline the accessibility, climate, and tenure (ACT) framework, based on the National Science Foundation ADVANCE initiatives. The ACT model requires an examination of curriculum requirements and accessible campus spaces. The ACT framework also encourages flexibility in the tenure process, such as reduced teaching hours and additional time to meet requirements.

Chapter 10 focuses on 31 student affairs practitioners' perceptions of students with disabilities. Study participants reported minimal disability-related training and felt unprepared to support students with disabilities. Participants were aware that students with disabilities demonstrate varying levels of self-determination skills, accommodation needs, and identity development. This chapter highlights the need for continuous disability-related educational opportunities.

Griffen and Tevis, in Chapter 11, summarize the results of their qualitative study of disability service providers at postsecondary institutions. Participants reported working diligently, even under budget constraints. The disability service providers also emphasized the importance of teaching students with disabilities self-advocacy skills. The results of this study support the authors' recommendation that postsecondary disability service providers collaborate with 
local K-12 schools to foster a smoother transition to college for students with disabilities.

Chapters 12-15, Part 4, combine research results and postsecondary practices to promote full inclusion of disabled students in higher education. In Chapter 12, Gabel, Reid, and Pearson discuss their study of whether California State University website developers represented disability in diversity marketing. Only one campus website referred to disability on a diversity webpage. The other 22 websites contained no images of students with visible disabilities, and only two pictures suggested the representation of hidden disabilities. The authors conclude that these results demonstrate the need to include disability representation in marketing materials and campus inclusion efforts.

Albaesi and Nusabum, in Chapter 13, discuss the themes of exclusion they found in the survey results of students with physical and/or learning disabilities at one institution. Participants identified physical barriers on campus as well as rejection in social situations. Other examples of exclusion included: microaggressions from parking office personnel toward students with hidden disabilities and faculty resisting accommodation requests. Study participants reported concern over the lack of disability-focused courses.

In Chapter 14, O’Neil Green, Willis, Green, and Beckman describe the Access Ryerson initiative at Ryerson University in Canada. This program views society's definition of normalcy as the root cause of exclusion for students with disabilities. Access Ryerson has three important parts: a structure based on defined ideals and beliefs, a senior leadership team, and small groups to implement the initiative. Access Ryerson seeks to remove physical and social roadblocks for students with disabilities by diminishing the need for individualized accommodations.

Kroeger and Kraus, in Chapter 15, provide a description of how disability service providers at the University of Arizona transformed their language and practice to integrate disability in all university functions. This chapter provides tangible examples of reworded policies that promote disability access as an institutional responsibility. Disability service providers train faculty on universal design for learning (UDL) standards and partner with their student engagement office to offer activities that present disability as an asset.

\section{Critique and Contributions}

An area absent from the preface of this book that would benefit readers is historical context. A summary of the disability rights movement (e.g., Nielsen, 2012) would deepen the argument of disability as a marginalized identity. A brief history of the field of disability studies would provide additional context. Disability studies scholars advocate using identity-first language to emphasize that societal barriers literally disable individuals (Dunn \& Andrews, 2015). Including this historical information at the start of the book would prepare readers for language variations within the text. The absence of a thorough history of disability makes this book most useful in upper-level undergraduate or graduate courses on disability studies.

This book exposes a gap in the preparation of faculty and student affairs professionals to serve disabled students. The cumulative information within the book exposes insufficient preparation for faculty, administrators, and staff to work with students with disabilities. The promotion of culturally relevant disability pedagogy, the ACT framework, and UDL standards would ensure inclusion at the forefront of class design, hiring practices, and student programming. This work reveals the need for additional professional development opportunities related to disability inclusion and access.

Book contributors advocate for higher education administrators, staff, and faculty to view disabled students as a marginalized group that needs intentional support. Postsecondary leaders will become familiar with the social, academic, and institutional barriers experienced by students with disabilities. Higher education personnel will find tangible recommendations to reduce barriers related to disability documentation 
requirements, social inclusion, building design, parking, and pedagogy. Readers will leave this text with an understanding of the necessity to incorporate disability access into their work, rather than confine inclusion efforts to campus disability service providers.

\section{Conclusion}

All postsecondary administrators and faculty members, regardless of their familiarity with disability, will find this book indispensable. Readers will find deep insights into the difficulties disabled students face. Postsecondary leaders will find opportunities to incorporate disabled students' needs into campus policies and procedures, which then provides definitive guidance for all students, faculty, and staff. Campus community members who adhere to disability inclusive policies will anticipate the needs of students with disabilities, create accessible campus environments, and reduce barriers. Postsecondary leaders who implement the strategies from this work will help create seamless access to campus life for disabled college students.

\section{References}

Aquino, K. C., Alhaddab, T. A., \& Kim, E. (2017). "Does Disability Matter?”: Students' Satisfaction with College Experiences. In E. Kim \& K. C. Aquino (Eds.), Disability as diversity in higher education: Policies and practices to enhance student success (pp. 47-60). New York, NY: Routledge Taylor and Francis Group.

Dunn, D. S., \& Andrews, E. E. (2015). Person-first and identity-first language: Developing psychologists' cultural competence using disability language. American Psychologist, 70(3), 255-264. doi: 10.1037/a0038636

Hutcheon, E. J., \& Wolbring, G. (2012). Voices of "disabled" post-secondary students: Examining higher education "disability" policy using an ableism lens. Journal of Diversity in Higher Education, 5(1), 39-49. doi. org/10.1037/a0027002

Martin, N. (2012). Disability identity-disability pride. Perspectives: Policy and Practice in Higher Education, 16(1), 14-18. https://doi.org/10.1080/13603108.2011.611832

McRuer, R. (2006). Crip theory: Cultural signs of queerness and disability. New York, NY: New York University Press.

Nielsen, K. E. (2012). A disability history of the United States. Boston, MA: Beacon Press.

Taylor, S. (2011). Disability studies in higher education. New Directions for Higher Education, 154, 93-98. https://doi. org/10.1002/he.438

\section{Recommended Citation:}

Burns, E. M. (2020). [Review of the book Disability as diversity in higher education: Policies and practices to enhance student success, by E. Kim \& K. C. Aquino, Eds.]. Journal of Critical Scholarship on Higher Education and Student Affairs, 5(2), 68-72. 
